\title{
Artelogie
}

artelogie Recherche sur les arts, le patrimoine et la littérature de l'Amérique latine

$8 \mid 2016$

Transgression dans les arts / transgression des arts

\section{Estética e transgressão: da arte radical à arte radicante}

Esthétique et transgression: de l'art radical à l'art radicant

\section{Ricardo Nascimento Fabbrini}

\section{OpenEdition}

\section{Journals}

\section{Edição electrónica}

URL: http://journals.openedition.org/artelogie/593

DOI: 10.4000/artelogie.593

ISSN: 2115-6395

Editora

Association ESCA

\section{Refêrencia eletrónica}

Ricardo Nascimento Fabbrini, « Estética e transgressão: da arte radical à arte radicante », Artelogie [Online], 8 | 2016, posto online no dia 26 janeiro 2016, consultado o 30 abril 2019. URL : http:// journals.openedition.org/artelogie/593 ; DOI : 10.4000/artelogie.593

Este documento foi criado de forma automática no dia 30 Abril 2019

Association ESCAL 


\title{
Estética e transgressão: da arte radical à arte radicante
}

\author{
Esthétique et transgression: de l'art radical à l'art radicant
}

Ricardo Nascimento Fabbrini

1 Em certa produção artística desde os anos 1990, é visível a tentativa de embaralhar arte e vida, o que a remete ao imaginário das vanguardas artísticas do século XX. Este intento, contudo, não pode ser identificado, sem mais, seja ao programa das vanguardas históricas dos anos 1910 ou 1920 como o dadaísmo ou futurismo, seja ao ideário contracultural das vanguardas tardias, como os happenings ou a body art dos anos 1960 ou 1970. É preciso, assim, distinguir o projeto vanguardista de estetização do real de propostas pósvanguardistas como a da "arte colaborativa" do "artista relacional" - nas expressões de Nicolas Bourriaud - que intentou, por outras vias, ou seja, sem nostalgia, reaproximar arte e vida, ou estética e política (BOURRIAUD, 2009: 51).

2 Recorde-se, de início, que no fim da década de 1980, no contexto do debate sobre a pósmodernidade, houve uma volta às linguagens da tradição evidenciada no retorno à pintura como nos ditos neoexpressionismo alemão, transvanguarda italiana, ou graffiti painting angloamercano que, com suas simbolizações, reagiram tanto à desmaterialização da arte, no happening ou na body-art, quanto à especialização ou ao hermetismo (no lugar comum do público) da arte minimal e conceitual da década anterior. Falava-se nesses anos 1980, portanto, de uma reação da arte pós-vanguardista ao formalismo extremado das vanguardas tardias por meio de um "retorno do real' na expressão de Hal Foster; o que significava que afastada a utopia, a arte pós-vanguardista destituída da força que se quis subversiva das vanguardas, reaproximava-se do presente ao denunciá-lo enquanto recrudescimento de conflitos étnicos, machismo, efeitos da globalização, ou crise da narrativa, reatando, por meio destas simbolizações, com o dito "mundo da vida" (FOSTER, $2001: 129$ ).

3 A expressão "retorno do real" vale recordar, foi utilizada por Hal Foster, a partir de Jacques Lacan, como a tendência a figurar no campo das artes, nos anos 1980, a 
experiência individual e histórica enquanto "trauma". Evitando medidas defensivas face ao "encontro falido com o real", como a tentativa de "tamisá-lo" pela simulação ou repetição - como em certas séries de Andy Warhol ou nas estruturas modulares da arte minimal - os novos artistas teriam se lançado ao "espetáculo do mundo", incorporando o "informe", a "abjeção" etc. Nas obras de artistas como Andrés Serrano e Cindy Sherman teríamos, nesta direção, a oposição entre interior e exterior, sujeito e objeto na "forma problemática" da "diferença". Seriam práticas artísticas que figurariam, segundo Foster, a política cultural de afirmação de diferentes subjetividades, sexualidades ou etnicidades na tópica do "trauma", do "real" ou do "referencial" (ou seja, do que é impossível, não obstante necessário, de se representar na realidade psíquica, na direção de Lacan). Esta contradição se evidenciou, segundo Foster tanto nas políticas identitárias (no sentido do multiculturalismo norte-americano) quanto na dita filosofia da desconstrução (como o pós-estruturalismo francês de Roland Barthes, Jacques Derrida ou Julia Kristeva). (FOSTER, 2001: 209-230).

Esta tentativa de "retorno ao real" adquiriu, contudo, nos anos 1990 outra configuração ; pois, reagindo à volta às linguagens da tradição como a pintura, escultura ou objetos da década anterior (o que levou, inclusive, ao reaquecimento do mercado de arte) a nova geração de artistas então emergente procurou reatar os vínculos práticos da arte com a vida sem a mediação destas linguagens; como se evidenciou na multiplicação de instalações (que deixaremos, aqui, de lado) e nos eventos de "arte participativa", em galerias, Bienais, ou no espaço público. O objetivo desse texto é, assim, tão somente, destacar aspectos de uma nova forma de baralhamento entre arte e vida haja vista que a arte relacional - na expressão utilizada por Nicolas Bourriaud para caracterizar essa nova modalidade de arte participativa (BOURRIAUD, 2009) - não assumiu as estratégias vanguardistas : nem a das vanguardas futurista, construtivista ou da escola da Bauhaus, que com sua fé na máquina, visavam pela estandardização dos protótipos formais criados pelos artistas, disseminar a arte no cotidiano ; nem à das vanguardas de raiz dadá-surreal, que, apostando no enguiço da máquina, intentavam pela poetização do gesto, ou seja, pela apreensão da irrupção súbita do "maravilhoso" no cotidiano (ao modo do acaso poético surrealista) a mescla entre arte e vida. Dito de outro modo: a estratégia dos artistas relacionais, nos anos 1990 a 2010, - que já foi associada à noção de "partilha do sensível" de Jacques Rancière (RANCIÈRE, 2005 :12) - de efetuar a fusão entre arte e vida não foi a da disseminação de objetos belos e úteis na vida, via design ou arquitetura ; e tampouco a de modificar a vida pela beleza do gesto, haja vista que o gesto estético oriundo do dandismo do século XIX, que foi ostentado pelas vanguardas dadá e neodadá não possui mais o ineditismo, como se sabe, ou sentido de ruptura. (GALARD, 1997:36). Basta observar que os meios pelos quais os vanguardistas esperavam alcançar a superação da arte, ou sua realização no mundo, 'obtiveram com o tempo o status de obra de arte' - como mostrou Peter Burger -, de modo que sua 'aplicação já não pode mais ser legitimamente vinculada à pretensão de uma renovação (radical) da práxis vital.' (BURGER, 2008:123 ; parênteses nossos). Face este diagnóstico resta examinar o sentido desta nova tentativa - indiciada na arte relacional ou radicante - de reatar arte e comportamento, intento que se poderia supor datado, porque inseparável do imaginário vanguardista.

Nicolas Bourriaud e Jacques Rancière afirmaram cada qual ao seu modo, que o período da utopia estética se encerrou, ou seja, que a ideia de um radicalismo em arte que investe em sua capacidade de transformação estrutural das condições da vida em sociedade não coloniza mais o imaginário artístico. $\mathrm{O}$ fim da ideia de que a arte possui poderes utópico- 
revolucionários, que orientou as vanguardas, não significa, entretanto, para estes autores, que a arte dita pós-vanguardista (como a arte relacional) não efetue crítica alguma à realidade do presente. Seria preciso, portanto, segundo esses autores, redefinir a relação entre estética e política - senão a própria noção de transgressão - evitando-se a simplificação da cena artística à oposição entre o poder de negatividade da arte de vanguarda, e a arte enquanto reafirmação da sociedade existente, com sua redução à condição de mercadoria cultural. Nosso desafio é, portanto, analisar - afastado esse esquematismo - as metamorfoses da mescla entre arte e vida, ou seja, a nova configuração política no "jogo de intercâmbios e deslocamentos entre o mundo da arte e da não-arte" (RANCIÈRE, 2005:53) que estaria em curso em certa arte contemporânea (ou pósvanguardista) desde os anos 1990 - aqui exemplificada na noção de arte relacional de Bourriaud.

Caracterizemos, inicialmente, sua posição. Em "Formas de vida", Bourriaud caracteriza o "projeto moderno" como uma "esperança de reconciliação entre arte e vida" no sentido de Jurgen Habermas (BOURRIAUD, 2011). Escapando ao caráter classificatório com pretensão totalizante das histórias da arte, esse livro examina a arte moderna a partir da relação entre ética e estética. A flânerie baudelairiana do fim século XIX, a errância surrealista nos anos 1920, assim como as "deambulações" da land art e as "derivas urbanas" dos situacionistas nos anos 1960 e 1970, intentaram, segundo o autor, "produzir a vida cotidiana enquanto obra de arte". (BOURRIAUD, 2011a:14). ${ }^{1}$ Seriam diferentes versões de uma mesma reação à reificação e à especialização das atividades segundo a "ideologia da racionalização do trabalho e da mecanização da sociedade", características do "processo global de acumulação do capital". (BOURRIAUD, 2011a:70). É essa "orientação ética" - esclarece Bourriaud - que também fundamentaria a "prática artística contemporânea", ainda que, diferentemente do período das vanguardas, o artista "nos dias de hoje" não busque mais a "reconciliação entre arte e vida" na "forma utópica da obra de arte total" (Gesamtkunstwerk), mas insira signos, pragmaticamente, no "cotidiano vivido", produzindo "alteridades possíveis". (Idem:168). O investimento da arte de vanguarda na "transformação do mundo" segundo "o esquema revolucionário" orientado por uma "utopia política", foi substituído, no diagnóstico do autor, por um "realismo operatório" voltado para a "utopia cotidiana, flexível" (ou "heterotopia") da arte relacional ou da pós-produção. (expressões utilizadas por Bourriaud, em "Estética Relacional", de 1998; e em "Pós-produção: como a arte reprograma o mundo contemporâneo"; de 2004).

7 Tomemos de início como exemplo de arte relacional as intervenções do artista argentino Rirkrit Tiravanija, destacadas não apenas por Bourriaud, mas também pelo crítico de arte e curador Hans Obrist. Em 1992, Tiravanija transformou a sala de exibição e escritório da "Galeria de arte 303", em Nova York, em um "espaço de encontros sociais" (OBRIST, 2006:79). O artista apresentou na sala vazia de exposição dois potes de curry e um de arroz para oferecê-los como almoço aos visitantes; armazenando no escritório da galeria os ingredientes da preparação da refeição assim como suas sobras, que mais tarde seriam convertidas em obras, fotos e vídeos - como lembra o artista - para "documentar esta situação" (OBRIST, 2006:80). Em "The Land" ("A Terra"), projeto iniciado em 1998, o mesmo artista implementou em uma propriedade em Chang Mai, na Tailândia, um "laboratório" em que "novos modos de vida" ou de "engajamento social" estariam sendo testados sob monitoramento de uma universidade local. É um "projeto de nítido fim social" - segundo o artista - uma vez que desenvolveria experiências com fontes 
alternativas de energia, como o biogás, além de utilizar técnicas tradicionais tailandesas na colheita, cujos frutos seriam distribuídos às famílias da região vitimadas pela AIDS (Idem:90-91).

8 Destaque-se também como exemplo de arte relacional a "situação" criada pelo artista holandês Jens Haaning - considerada emblemática dos anos 1990, por Bourriaud intitulada "Turkish jokes" ("Piadas turcas"). Haaning dispôs um alto-falante em uma rua de Copenhague e outro em Bordeaux com gravações de piadas em turco e em árabe. 0 resultado, segundo relatos, é que somente as pessoas que entendiam esses idiomas se aproximavam do alto-falante para então permanecerem, divertidas, em torno dele, compondo uma "escultura temporária", na expressão do artista (BOURRIAUD, 2008:33). Acrescentemos, ainda, como exemplo de arte relacional, avançando nos anos 2000, a mostra "Insite 05", que se realizou na fronteira entre San Diego, na Califórnia, e Tiijuana no México. Na seção "Intervenções" dessa edição de 2005, o artista venezuelano Javier Téllez coordenou um processo com pacientes de um centro de saúde mental mexicano, que colaboraram com o artista na organização de performances: "Os pacientes - descreveu um crítico de arte na ocasião - não só confeccionaram as bandeiras penduradas na cerca, como também realizaram encenações sobre fronteiras espaciais e 'mentais", tema recorrente do artista venezuelano. (CYPRIANO, 2005:E-10).

Essas intervenções teriam por finalidade, segundo Hans Obrist, construir "espaços e relações visando à reconfiguração material e simbólica de um território comum" (OBRIST, 2006:17). "Mediante pequenos serviços" - corrobora Bourriaud - elas "corrigiriam as falhas nos vínculos sociais" ao "redefinirem as referências de um mundo comum e suas atitudes comunitárias" (BOURRIAUD, 2008:26). Sua finalidade seria constituir durante certo tempo, - agora nos termos de Tiravanija -, novos espaços de interação - "plataforma" ou "estação": "um lugar de espera, para descansar e viver bem", em que "as pessoas conviveriam antes de partirem em direções distintas". (BOURRIAUD apud OBRIST, 2006a:81). Seria, em suma, para o crítico, o curador, e o artista um lugar de "esperança e mudança", porém "não nostálgico", porque dissociado da ideia já devidamente arquivada, que orientou as vanguardas, - de utopia. Essa também é a posição, em linhas gerais, de Jacques Rancière, para o qual manifestações artísticas que promovem a "partilha do sensível", não se propõem a produzir a experiência de uma alteridade radical por meio da "singularidade da forma artística", mas "redefinir situações e encontros existentes" a partir da "re-disposição dos objetos e das imagens que formam o mundo comum já dado" (RANCIÈRE, 2005:46). Estes artistas visariam a evidenciar práticas - "modos de discursos", "formas de vida" que operariam como resistência à sociedade do espetáculo. (RANCIÈRE, 2005: 50). Seu objetivo, em síntese, seria criar condições de possibilidade para que experiências comunitárias se exteriorizassem; ou, nos termos do próprio Rancière, "desenhar esteticamente" as "figuras de comunidade" recompondo deste modo a "paisagem do visível" : a "relação entre o fazer, ser, ver, dizer." (RANCIÈRE, 2005:52).

Em seu livro mais recente, "Radicante: por uma estética da globalização" Bourriaud mantendo-se na mesma direção, destaca a produção de artistas contemporâneos que assumindo a "postura ética" da arte de vanguarda procura, no entanto, "inventar novas relações com o mundo", e não "criar um mundo fundado em novas relações" no sentido das vanguardas artísticas (BOURRIAUD, $2011: 123$ ). O autor privilegia neste texto as "práticas" referentes aos deslocamentos geográficos dos artistas, alguns deles mencionados em "Estética Relacional”, expressão que, agora, evita. 0 “artista radicante" é 
tomado pelo autor como sintoma de um mundo marcado pela mobilidade resultante da porosidade das fronteiras entre estados nacionais ; das migrações ; do turismo crescente ; dos fluxos econômico-financeiros acelerados; ou das navegações pela internet. A figura emblemática de nossa "era precária" seria, assim, na convicção de Bourriaud, a "viagem", ou "errância." (BOURRIAUD, 2011:51). Os artistas radicantes seriam, portanto, "inventores de percursos", nômades que, amealhando signos, constituiriam novas "paisagens culturais" (BOURRIAUD, 2009b:34). "Radicante" esclarece o autor, é a planta que possui várias raízes ou a que é capaz de produzi-las sempre que replantada; de modo que o artista radicante seria, por analogia, aquele que, não fincando raízes em um só território, possibilitaria, com seu nomadismo, "trocas culturais" (BOURRIAUD, 2009b: 12). Seria radicante o artista que, sem calcinar suas primeiras raízes, se abriria ao longo de sua trajetória a sucessivos replantios, os quais frutificariam de acordo com o solo que os acolhesse. Dessa "aclimatação" aos diferentes territórios brotariam "traduções culturais" ou "laboratórios de identidades", noções semelhantes às de "plataforma" ou "estação" apresentadas em seus livros anteriores: lugares em que o artista e o público compartilhariam, durante certo tempo, "novos modos possíveis de habitar" o "mundo existente". (BOURRIAUD, 2009:111).

11 Essas "negociações culturais" deflagradas por um "povo móvel de artistas", em "marcha pelo mundo", é o que singularizaria a "altermodernidade": a "modernidade do século XXI" (BOURRIAUD, 2009b: 41). Essa "nova categoria" visa a rejeitar tanto o sentido de modernidade artística do século passado, inseparável das ideias de vanguarda, progresso, utopia, colonialismo ou eurocentrismo, quanto à noção de pós-modernismo, enquanto ecletismo ou multiculturalismo. Bourriaud recusa, em outros termos, tanto o "universalismo moderno" do período das vanguardas artísticas europeias e, após a segunda grande guerra, norte-americanas, como o "relativismo pós-moderno", ou "póscolonialista", que afirma a coexistência de "identidades culturais" enquanto "diferenças exóticas" a serem preservadas no sentido do cultural studies. (BOURRIAUD, 2009b:170-188). Reagindo às formas "identititárias", as "obras altermodernas" produzidas por um "povo móvel de artistas", habitantes do êxodo ou do "mise-en-route" (nova versão da plataforma ou estação apresentada em seus textos anteriores), agenciariam um "acordo produtivo" (" en accordant") entre discursos singulares. (BOURRIAUD, 2009b:48). Nessa direção, as obras radicantes possibilitariam a construção de "espaços de negociação". Seriam obras que não figurariam, na intenção de Bourriaud, 'identidades fixas e estáveis', mas 'identidades abertas, contraditórias inacabadas, fragmentadas'. (BOURRIAUD, 2009b: 56). Possibilitariam pensar os deslocamentos dos códigos a partir da tradução, pelo artista, das línguas de partida e chegada sem que nenhuma delas tivesse, no ato de transposição, sua raiz calcinada. Face isso, cabe, porém, desde já, um senão, a saber : esse reconhecimento, sem mais, do artista de outras nacionalidades, ou de obras que apregoam seraficamente tolerância, endossando aqui, a discursividade conciliatória do mundo - à qual voltaremos - implica, muita vez, abolição de critérios de julgamento estético; e, por conseguinte como já assinalou Slavoj Zizek - "colonialismo ao inverso" (ZIZEK, 2003 :44). De fato : quando a crítica de arte converte o outro, em fantasma a exorcizar seus fantasmas; ou seja, em sujeito de uma verdade histórica e política a ser prontamente reconhecida, independentemente da articulação do dito conteúdo na forma artística - como também assinalaremos - a arte se faz etnologia, sociologia ou antropologia ; uma vez que a forma artística acaba, nesses casos, destituída de sua autossuficiência ou arbitrariedade, condição necessária de seu poder (transgressivo) de dissolver consensos. 
Deve-se acentuar, ainda, que na caracterização da "subjetividade emergente" nos espaços de arte radicante, Bourriaud relaciona, não sem problemas, os anos 1960 e 1970 aos anos 1990 a 2000. Nas "cartografias alternativas" da arte da pós-produção (estética relacional ou arte radicante), a "subjetividade do artista" não se constituiria, para o autor, enquanto "identidade estável e fechada sobre si mesma", mas como "construção", sempre temporária, ao longo de uma trajetória errante, mediante "atos sucessivos de tradução cultural". (BOURRIAUD, 2009:122-123). Deixando de lado a imprecisão da noção de "tradução" que perpassa o livro "Radicante: por uma estética da globalização", acentuese, tão somente, o uso sui generis por Bourriaud da noção de "subjetividade esquizo" de "O Anti-Édipo" (1973) e "Mil Platôs" (1980), de Gilles Deleuze e Félix Guattari. Em outros termos é preciso distinguir os "fluxos descodificados" e "desterritorizados" que deslizam pelo "corpo do socius", no sentido das "micropolíticas do desejo" e da "revolução molecular", na língua de Deleuze e Guattari, do "relato dialogado entre o sujeito e as situações que ele atravessa, e nas quais prende suas raízes", no sentido das "trocas culturais", em Bourriaud (BOURRIAUD, 2009b:126). Ou seja : o artista radicante não é movido pelo intento de libertar a potência revolucionária do desejo, abrindo-se à imponderabilidade do devir, mas pela ideia de "negociação (trocas ou traduções) infinitas", enquanto prática intersubjetiva análoga a do agir comunicativo esteticamente motivado, conforme o paradigma da comunicação. (BOURRIAUD, 2009:54). De modo singular, Gilles Deleuze e Jurgen Habermas cohabitam sem atrito, vale ressaltar, a plataforma literária, feita de mixagens, de Bourriaud. Em síntese : atentar para a arte radicante da "altermodernidade", núcleo de seu último livro, permitiria, segundo Bourriaud, realizar uma análise nuançada da relação da produção contemporânea com a modernidade artística haja vista que essa produção não proporia nem o mero resgate da arte de vanguarda, nem sua simples refutação, mas repensá-la segundo as contradições do presente. Essa tentativa, contudo, de legitimar a arte radicante relacionando-a a arte radical vanguardista - mesmo admitindo as mudanças no imaginário artístico no curso do tempo - é dificultosa, como veremos.

Destaque-se, contudo, antes de acrescentar outros senões às noções de Bourriaud, dois exemplos de "artistas radicantes", entre a centena que o autor amealhou, em seu último livro. 0 primeiro exemplo são as intervenções de Dominique Gonzáles-Foerster, referida frequentemente pelo autor, que exibiu na Documenta de Kassel, em 2002, Park : a plan for escape (BOURRIAUD, $2011: 72)$ : "No meio do imenso parque arborizado da cidade", a artista criou um "espaço feito de elementos díspares" (vinte objetos) oriundos dos diferentes países em que passara temporadas, tais como: um "orelhão" azul do Rio de Janeiro ; roseiras de jardim de Le Corbusier em Chandigarh ; um pavilhão em forma de borboleta exibindo um filme baseado no livro "A Invenção de Morel", de Bioy Casares; postes de iluminação de Grenoble; sete toneladas de pedra vulcânica do México ; uma palmeira; uma rede, um caminho de areia; entre uma série de outros elementos" (BOURRIAUD, 2011 :73). São "objetos de natureza desigual" que "compartilham uma existência simultânea" sem qualquer hierarquia ou coordenação que os vincule, salvo a intenção da artista em elegê-los (PATO, 2013:257). Trata-se aqui, segundo Bourriaud, de uma "apresentação direta da matéria exótica mediante uma transferência operada pela forma": "um espaço mental radicante, surgido de uma diáspora de signos implantados em um solo circunstancial" (Idem, 2011:72d). De maneira semelhante, a artista semeou, comenta Ana Pato, na "grama verde do parque, objetos que formam um conjunto de referências incompletas, aberto à imaginação de espectadores e turistas" (PATO, 2013:60). 

esculturas de artistas renomados como as de Donald Judd, de 1977 ; de Claes Oldemburg, de 1987; de Ilya Kabakov de 1997, entre outras, reduzidas em tamanho na escala $1: 4$ (a 25 \% do original), apresentadas pela artista, na quarta edição do Skulptur Projekter Munster, em 2007, exposição que a cada dez anos converte a cidade de Munster, na Alemanha, em museu aberto de esculturas contemporâneas. Nesses "ambientes" de Foerster temos signos salpicados em parque ou jardim que constituiriam, segundo Pato, "um espaço para a evasão de sentidos preestabelecidos": "uma área precisamente delimitada que poderia ser uma rota de fuga"; um "espaço real" que "nos permitiria escapar da imagem", tomada certamente, pela autora, como estereótipo, ou fórmula protocolar mass-midiática ou do mundo digital. (PATO, 2007: 68). Não se trataria de visar à produção de uma imagemenigma que na rasura de clichês indiciasse algum segredo, mistério ou recuo, a partir da estrutura da obra, uma vez que o desafio do fruidor, segundo a artista, não seria a "decifração da forma artística", mas sua capacidade em costurar livremente signos descosidos. (FOERSTER apud PATO, 2013:260).

Esses "ambientes de signos em dispersão" são caracterizados por Foerster, com endosso da crítica, como "arquivos ou enciclopédias", muitas vezes constituídos a partir dos acervos e bibliotecas das instituições de arte nas quais a artista expõe sem a intenção crítica de "desconstruir essas instituições" (diferentemente, portanto, da tradição de Marcel Duchamp a Hans Haacke). (FOERSTER apud PATO, 2013:253). Forester não atribui, assim, a Roman de Munster a "tentativa de dessacralizar o espaço da arte", no sentido da tradição vanguardista. Seu regime seria antes o do encômio, e não o do vitupério de raiz dadá, ou o epidítico, enquanto descrição de operações artísticas, da arte conceitual de Joseph Kosuth ou do grupo "Art \& Language". "Há um deleite em jogar com as escalas. Como quando concebi as esculturas gigantes em TG2058 que diferentemente de Roman de Munster não reduzem, mas ampliam em 1:4 em cópias cenográficas" as esculturas de Alexander Calder, Henry Moore, Louise Bourgeois ou Bruce Nauman, "que expus, em 2008, na Turbine Hall da Tate Modern" (o mesmo espaço que fora ocupado, em 2005, diga-se de passagem, pelo Tangled-Tubes, o tobogã do suíço Carsten Holler); "Quer dizer continua a artista - que é uma adoração brincalhona, claro; acho muito divertido ter a aranha de Louise Bourgeois abraçando o flamingo de Calder; é o que fiz também em Munster, com tantas escalas diferentes. Mas é mais uma grande brincadeira (essa aproximação em TG2058 entre o museu de arte e o museu natural) que uma ação destrutiva". (FOERSTER: apud PATO, 2007:276; parênteses nossos). Em suma: na obra transformada em brinquedo, em Feira de Variedades, em Park: Plan for scape ; em Casa de Miniaturas, em Roman de Munster; ou em Arca de Noé Artística, em TG2058, temos o mesmo assentimento, a julgar pelo depoimento da artista, à concepção de museu como entretenimento, que se consolidou, como se sabe, nas últimas décadas. É claro que um observador concessivo, movido pelo adágio in dubio pro artista, na tentativa de atribuir dimensão crítica, ou política, à sua obra, pode tomar a mudança de escala, como dispositivo irônico que problematiza a relação entre original e cópia, senão a própria musealização da arte, enquanto arquivo. Mesmo assim, há que se ponderar se essa apropriação calcada na alteração de escala de "esculturas célebres" é eficaz ao ponto de evidenciar "os diagramas de poder que atuam na arte contemporânea", como almeja Pato.

Os "ambientes" de Foerster são tidos também como "literatura expandida" na linhagem de Jorge Luis Borges, ou Enrique Vila-Mattas, mescladas às ficções científicas "distópicas" de J. G. Ballard, nos comentários do próprio Vila-Mattas, que avaliza essa genealogia de 
fina extração, proposta pela artista: "Quando penso em um tipo de arquivo, visualizo-o na forma de gráfico, com pontos interligados, que mantêm várias relações (intertextuais)". (FOERSTER, 2013:263 ; parênteses nossos). Para designar sua estratégia de "perverter, reduzir ou agigantar o original" - o que implicaria a revisão da ideia de arquivo na perspectiva de Michel Foucault enquanto discurso de poder, segundo Pato - Foerster, essa "grande amante da arte das citações", utiliza termos variados como "citação corrompida", "citação monstruosa", colagem ou montagem : "no final, diz a artista referindo-se aos seus ambientes tão cheios de signos" - "tudo é um grande trabalho de edição, de montagem" (VILA-MATAS apud PATO, $2013: 244$; 251). O agenciamento de signos - "esse jeito de ligar as coisas", inclusive diversas linguagens artísticas como vídeo, objetos, ou esculturas - seria análogo, segundo a artista, ao "modo de leitura no computador", na medida em que teríamos, em ambos os casos, "colagem de fragmentos", como na intertextualidade da "alta literatura", de Cervantes ao OuLiPo (Ouvroir de Littérature Potentielle de Raymond Queneau e Georges Perec). A suposição, passível de questionamento, é a de que a obra desses escritores "se conecta profundamente à forma como a internet funciona hoje". (PATO, 2013:184). Desses depoimentos depreende-se que a labilidade no uso dos termos, por parte da artista e da crítica, repõe em circulação o debate dos anos 1980, sobre os modos de apropriação da tradição artística (moderna e pós-vanguardista), tais como montagem, colagem, pastiche, citação, revival, remix, reciclagem, repetição, paródia, reencenação, cover, pós-produção etc. Portanto, o desafio, nesse caso, é saber como se dá a relação entre os signos na heterogeneidade de livros, filmes, ou esculturas mobilizada por Foerster, também caracterizada pela artista como "biodiversidade cultural" (FOERSTER: apud PATO, $2007: 276$ ).

17 Esse desiderato como dizíamos, de fazer com que a "obra" escape à imagem-feita, tantas vezes reiterado em depoimentos de Foerster, ou seja, de que o "ambiente" se "furte às classificações fechadas e teleológicas”, na afirmação do crítico e curador Carlos Basualdo, pode, em virtude da abertura excessiva do campo de significação (ou de informação), descarrilar em "confusão ou desordem especular de imagens", aproximando-se, malgrado o intento da artista, de uma ciranda aleatória de clichês (PATO, 2013 :67). Pois, afinal, trata-se de "uma reação à saturação e ao excesso de informações e de imagens", ou, em sentido inverso, o seu prolongamento ou replicação? (PATO, 2013 :194). É evidente que como reitera a artista, é o fruidor que atribui um sentido aos objetos, mas não se pode ignorar que há, no campo da arte, uma dialética entre a obra proposta e a experiência do fruidor; de tal sorte que sem um campo de possibilidades que oriente as escolhas do fruidor, resta - como dizia Umberto Eco - a recaída na "indistinção, no indeterminado de um estado selvagem de significação". (ECO, 1976:162). Em suma: se estes ambientes de signos em dispersão, não se organizam mais esteticamente em um aparato de significantes aberto e ambíguo (ou seja, em função de uma tensão interna aos agrupamentos visuais), o que lhes atribuiria eficácia?

Segundo exemplo de artista relacional, recorrentemente mencionado por Bourriaud, é Rirkrit Tiravanija, já referido acima, que organizou por sua vez, em 1998, "uma expedição de um mês em um motor-home" pelos "locais míticos da cultura norte-americana" como o Grand Canyon e a Disneylândia na companhia de cinco estudantes de arte tailandesa (BOURRIAUD, 2009:125), sendo que durante o percurso o artista e sua equipe disponibilizavam as informações coletadas em um website, e produziam vídeos, exibidos posteriormente no Museu da Filadélfia. Essa expedição, segundo Bourriaud, criou por meio de "processos de filtragens", "cartografias alternativas do mundo contemporâneo"; 
ou seja, "ativando o espaço através do tempo e o tempo através do espaço", Tiravanija teria recusado "insidiosamente" - ainda na intenção do autor - a paralisia da experiência viva nos estereótipos do turismo cultural global. (BOURRIAUD, 2011:126).

19 Estas ações "transdisciplinares" de arte relacional ou radicante até aqui mencionadas, suscitam questões, como dizíamos, que devem ser esmiuçadas. o primeiro aspecto é o da efetividade da forma artística, seja evento ou instalação, de arte relacional ou radicante. 0 segundo aspecto é a singularidade da apropriação de signos, nesta "cultura de uso comum". O terceiro é a relação entre arte, sociedade e comunicação envolvidas nestes dispositivos que visam tornar públicas as práticas sociais de dado território. Finalmente, o último aspecto a ser relevado é a confluência entre a tarefa da crítica e a função de curadoria verificada no processo de legitimação dessas "práticas colaborativas".

Nas "plataformas" de arte colaborativa há a disposição de objetos ou imagens apropriados do "mundo compartilhado" em galerias de arte ou no espaço público. Essa disposição, no entanto, que não implica, necessariamente, - cabe adiantar - linguagem artística enquanto arranjo formal e tampouco a "autofundação de um espaço plástico", como a intentada em certas pinturas ou instalações, vanguardistas ou não (LYOTARD, 1997:96). Se as linguagens artísticas buscam prazer estético entendido como páthos, como "experiência da interrupção dos momentos e dos lugares" - "algo como: comunicação sem comunicação", no sentido da interpretação da estética do sublime por Jean-François Lyotard, - a arte colaborativa visa comunicar em intrigas ou narrativas, "trocas interculturais". (LYOTARD, 1997:113). Nesta "cultura da atividade", enfim, a arte renuncia às leis internas, a autonomia da forma artística historicamente conquistada no período das vanguardas, pois o artista utiliza-se de objetos ou imagens disponíveis com a finalidade de dar visibilidade a uma situação social vivida na colaboração entre o artista e o público - dispositivo que não pressupõe preocupação formal ao menos no sentido da "obra de arte autônoma". Dito de outra maneira, cabe perguntar se nas obras de arte relacional a realidade existente é reconfigurada na lógica interna da forma artística de modo a constituir-se enquanto poética, porque sem esta elaboração - que permite articular estética e política - a obra acaba, malgrado o intento do artista, reduzida a prolongamento desta mesma realidade. Resumindo: há um déficit de análise da forma artística nos textos de Bourriaud, haja vista que o autor não mostra como Tiravanija, Haaning; Téllez e Foerster engendram linguagem poética a partir de elementos da realidade empírica. Essa renúncia à forma artística já foi assinalada por Jacques Rancière, que, em crítica pontual a Bourriaud, afirma que este elimina "a mediação entre a arte produtora de dispositivos visuais e a transformação (visada) das relações sociais" (BOURRIAUD, $2011: 69$ ) ; ou, em outros termos, que "os dispositivos de arte" enumerados por Bourriaud visam a produzir diretamente "relações com o mundo" - portanto, sem sua devida reconfiguração na lógica interna à forma artística - "formas ativas de comunidade", "meetings, reuniões, manifestações, diferentes tipos de colaboração entre pessoas, jogos, festas lugares de convívio"; em síntese : "diversas propostas de relações sociais" (BOURRIAUD, $2011: 69$ ).

21 É preciso acentuar, ainda, que segundo Bourriaud, a arte contemporânea questiona justamente a ideia de "sintaxe da forma artística" que vigorou no período das vanguardas, pois "não se trataria mais de gerar sentido através de signos representados", mas "de produzir relações com o mundo" (Idem:157). O pressuposto de Bourriaud é que "a esfera das relações humanas como lugar da obra de arte não tem precedentes" na história da arte, apesar do happening, ou da performance dos anos 1960 e 1970. (BOURRIAUD, 2009:61). 
Sendo assim, se a "arte relacional produz relações humanas" prescindindo da forma artística, "'a primeira pergunta a se fazer é quais tipos de relações estão sendo produzidas, para quem, e por quê?". (BISHOP, 2004:65). E ainda: sendo que o artista não "elabora uma forma a partir de um material bruto", mas "seleciona objetos em circulação" ("formas dadas") cabe perguntar pela natureza da seleção e da relação estabelecida entre esses objetos na "produção de relações humanas". (BOURRIAUD, 2008:9). Como o artista "não fundamenta mais uma obra na expressividade estrutural de signos", Bourriaud limita-se, então, a indicar laconicamente, como "princípio compositivo" da arte atual, a "navegação sinuosa" pela "constelação de signos". (BOURRIAUD, 2011:101). É o que se verificaria na arte radicante, que coloca "em cena uma massa crítica visual através da acumulação caótica de informações e formas produzidas pela indústria", cabendo ao espectador "traçar um percurso pessoal em meio a este excesso de informações" (BOURRIAUD, 2011:117). Embora Bourriaud afirme que o "artista da pós-produção" "conecta níveis heterogêneos de discurso", como essas conexões - os "modos de tratamento" dos "pacotes de informação" - nunca são especificadas, suas obras acabam limitadas, aos olhos do leitor, a pots-pourris de signos descosidos que envolvem o corpo sensório-motor do público - o "novo academicismo da arte contemporânea", segundo Rosalind Krauss. (BOURRIAUD, 2011:125). Em resumo: renunciando à ideia de sintaxe da forma artística (que pode ser estendida à poética do gesto e à instalação) a arte radicante no intento de relacionar-se imediatamente com o mundo, parece sucumbir, não raras vezes, às exigências de comunicação impostas pelo mercado e pela indústria do entretenimento.

o segundo problema da arte relacional ou radicante são as referências mobilizadas pelo autor para enraizá-las na tradição da arte moderna. Bourriaud aproxima, por exemplo, "a produção de formas mediante coleta de informações" da "cultura do uso" de Marcel Duchamp, que nos anos 1910, como se sabe, introduziu alterações em objetos utilitários com a finalidade de exibi-los como obras de arte. Estas operações estariam na raiz da "cultura do uso" a partir dos anos 1990, porque o artista relacional também recolheria, como Duchamp, objetos do cotidiano para modificá-los segundo uma "intenção específica", como ocorreria, por exemplo, com Tiravanija que se apropriou tanto de imagens disponíveis de espaço vazio como as de Yves Klein de 1958 ; de Jannis Kounellis, de 1969 ; ou de Michael Arher de 1974 ; como também de objetos diversos, como bujões de gás, potes, fogões e cadeiras, em seu almoço oferecido aos visitantes da "Galeria de arte 33", em Nova York, como vimos (BOURRIAUD, 2009 :22).

Esta paternidade de Marcel de Duchamp exige, todavia, cuidadosa investigação. Nos últimos anos tem sido tão frequente a apropriação pela crítica de arte dos ready-mades de Duchamp na tentativa de interpretar a arte pós-vanguardista que é possível até mesmo indagar se o próprio artista não acabou convertido, malgrado seu intento, em ready-made. É preciso lembrar, contudo, que em um ready-made, como dizia Gérard Genette, "a obra não é o objeto exposto, mas o fato de se o expor' (GENETTE, 1994 :155) ; e que a repetição do mesmo ato - contrariando o lema de Duchamp : "Não repetir apesar do bis" - acarretou a degradação imediata do estranhamento, sua recaída no gosto e o deslocamento de seu sentido originário, de modo que esse ato não causa mais polêmica no público, nem produz a desestabilização das categorias da crítica. Não é esse o intento, inclusive, dos artistas relacionais que, diferentemente de Duchamp, não visam a promover objetos triviais, livremente escolhidos, a condição de obra de arte ao introduzi-los em galerias ou museus com a finalidade de questionar seu estatuto. Com o pot-pourri de objetos dispostos no 
espaço esses artistas buscam, antes, criar condições de possibilidade para a coabitação provisória de um território; ou, como dizíamos: habitar "plataforma “ ou "estação". Estes materiais reunidos não constituem também - à revelia de Bourriaud - bricolage, collage, assemblage ou fotomontagem, meios pelos quais os artistas vanguardistas acreditavam embaralhar arte e vida. Porque nestes casos, como mostrou Peter Burger, podíamos falar ainda de sintaxes artísticas, não no sentido da composição sintagmática, por subordinação das partes ao todo como na "arte orgânica" ou "simbólica" (atribuída à tradição anterior às vanguardas); mas enquanto composição paratática, por justaposição de elementos no sentido da arte inorgânica, ou alegórica - como a arte de vanguarda. Não se pode, por conseguinte, afirmar em consonância com a tradição vanguardista, que uma plataforma ou estação objetive como efeito o choque, pois este adviria da experiência de "denegação do sentido" efetuado pela montagem, como, por exemplo, em um merzbau de Kurt Schwitters ou em um papiers collés de Raoul Hausmann, dos anos 1920. (BURGER, 2008:158).

Essa apropriação de Duchamp por Bourriaud também é problemática porque o uso de materiais pelos artistas relacionais seria semelhante ainda, segundo o autor, às operações nos sistemas técnicos de informática ou, em sua própria expressão, às "tecnologias da pós-produção". É por isso que "deejaying e arte contemporânea seriam figuras similares" (BOURRIAUD, 2009:40). O artista relacional, como herdeiro de Duchamp, se aproximaria do sampleador ou do internauta, pois em todas estas atividades teríamos reciclagem, seja de "sons, imagens ou formas", resultado de "navegação incessante pelos meandros da história cultural". (BOURRIAUD, 2009:54). E mais: a rave, no qual "a obra de arte torna-se o local de um scratching permanente", seria um símile do evento relacional, porque nos dois casos a oposição entre emissor e receptor - combatida pelas vanguardas dadás e neodadás - teria sido finalmente superada por uma nova modalidade de fruidor: a do "usuário", enquanto "operador de formas". (BOURRIAUD, 2009:41). Não se pode esquecer, contudo, que Duchamp criticou, com seus bric-à-bracs irônicos ou engenharias gaiatas, a noção de uso no sentido da racionalidade técnica segundo fins. Recorde-se que seus inutensilios tinham como objetivo estancar o movimento, ou ao menos desacelerá-lo, como reforça o próprio silêncio cioso do artista, enquanto o DJ recoloca os signos, uma vez modificados, a ressoar em balada ou batida ininterruptas. Em outro tom: em MD temos ralanti: nada ou quase uma arte, próprios à estética da recusa de Mallarmé, Rimbaud ou Cage; enquanto no DJ temos agito-próprio, techno pop, ao modo flash mob. De fato : o fruidor da arte de vanguarda foi substituído pelo usuário de formas; mas este pode ser equiparado ao "consumidor cultural" supostamente "inteligente e potencialmente subversivo", que, face à mistura de "signos disparatados" em um environment dançante (na deejaying art) conclui "que tudo se equivale porque tudo é bom para consumir"; reforçando a ideia de que o "ecletismo do consumo de formas-miscelâneas" está a serviço do "mundo tecnocientífico e pós-industrial" do capitalismo global, no juízo de Lyotard sobre a pintura dos anos 1980, que aqui estendemos à arte relacional dos anos 1990. (LYOTARD, 1996:206).

É preciso verificar, ainda, passando ao terceiro problema se nesta "cultura da pósprodução", ligada ao mundo da apropriação em que as fronteiras entre consumo e produção teriam sido eliminadas, a arte não acabou reduzida a uma forma corriqueira de comunicação. Sabe-se que as obras desde os anos 1980 'demitidas das exigências de projetos, utopias, e programas tem enfrentado os problemas colocados pelas demandas de comunicação' (FAVARETTO, 1991:149). Liberada do imperativo das vanguardas de tornar a arte esfera autônoma os artistas tem se voltado, desde então, aos problemas do presente 
(segregação étnica, crise do ecossistema global, ou de liberdade de comunicação da rede) procurando "satisfazer tal demanda, mesmo arriscando-se a sucumbir às exigências de comunicação impostas pelo mercado". (Idem:149).

Retornando a Rirkrit Tiravanija, recorde-se que o artista reapresentou na $28^{\mathrm{a}}$. Bienal de São Paulo, de 2008, uma "situação" em que problematizava justamente a comunicação: "mesas de negociação, estranhas plataformas de discussão, cenas vazias, painéis de cartazes, pranchetas, telas, salas de informação - estruturas coletivas, abertas a participação do público" (BOURRIAUD, 2009:65). Seu objetivo era constituir ágoras residuais, espaços de negociação do sentido - o que remete tanto ao intento, já descrito, da arte de "retornar ao real" como ao paradigma do "agir comunicativo" de certa filosofia contemporânea - que suprissem a ausência desses espaços na dita sociedade do pensamento único. Esta tentativa, porém, de pelo "arquivamento e testemunho de um mundo comum" reagir às limitações da democracia representativa ou ao controle das informações no circuito das mídias só adquire efetividade, paradoxalmente, como se sabe, se convertida em evento cultural por estas mesmas mídias. (BOURRIAUD, 2009:75).

O problema, agora, é saber se a arte relacional quando "mise en situation nos meios de comunicação" preserva "as realidades advindas de sua própria forma artística", podendo "ser julgada como tal", ou "se elas se tornam apenas tributárias da imagem que dela a comunicação pode fazer circular" (CAUQUELIN, 2005:81). Porque se analisarmos os mecanismos de produção e distribuição da arte contemporânea perceberemos, com Anne Cauquelin, que plataformas como a ágora de Tiravanija "se constrói fora de sua qualidade própria - a da participação in situ dos colaboradores - mas na imagem que ela suscita dentro dos circuitos de comunicação" (CAUQUELIN, 2005:82). Ou seja: essa convergência entre arte e comunicação é reciprocamente interessada; haja vista que para que "a sala de conferências" da $28^{\text {a }}$. Bienal de São Paulo não ficasse restrita aos interlocutores especializados era preciso que ela circulasse - uma vez convertida em imagem digital - na sociedade da comunicação. Além disso, "a criação artística é a atividade mais requisitada, mais demandada, e talvez a única que convenha perfeitamente à circulação de informações sem conteúdo específico", capaz, por esse motivo, de "assegurar o funcionamento do mundo mass-midiático em seus aspectos exclusivos de rede" como mostra Cauquelin (2005, p. 165). Dessa dependência recíproca entre arte e comunicação resulta, assim, o risco da redução da ágora de Tiravanija, malgrado o intento do artista, a seu simulacro, à imagem descarnada mass-midiática.

Resumindo : o desafio é saber se as "práticas colaborativas e interdisciplinares" descritas por Bourriaud e Obrist, que intentam, cada qual ao seu modo, aproximar arte e vida, articulam os elementos do presente no gesto estético ou na forma artística de modo a relacionar, na metáfora, estética e política; ou, se essas práticas, ao contrário, uma vez reduzidas à esfera da comunicação, na qual predomina as funções fática e referencial da linguagem, atestam simplesmente a neutralização da função poética ou o desvanecimento da política, sucumbindo ao dito mundo colonizado da vida. ${ }^{2}$

Ressalve-se, em quarto lugar, que enquanto para Bourriaud e Obrist as proposições dos artistas relacionais seriam uma reação "ao estreitamento do espaço público e do desaparecimento da invenção política na era do consenso" (RANCIÈRE, 2005a, p. 54), para outros críticos - como estamos procurando mostrar -, diferentemente do gesto estético dos anos 1960 que visava a renovação da sensibilidade por meio de um "apelo às forças que impelem o espírito para a fonte originária dos conflitos", no sentido, por exemplo, dos happenings e body art (COHEN, 1988, p.43), a colaboração na arte relacional 
representaria uma forma edulcorada de crítica social. Essa é a posição, por exemplo, da crítica Claire Bishop, já referida, segundo a qual esta participação do público produziria um "sentimento de empatia, de coabitação comunitária"; uma vez que quem habita provisoriamente uma plataforma - como as de Tiravanija, Téllez, Haaning ou Dominique Foerster - viveria a experiência de uma "humanidade reconciliada" ; o que acarretaria a despolitização da arte em razão da refutação de toda forma de oposição ou de violência no campo social (BISHOP, 2004, p. 96).

Nessa mesma direção, Jean Galard conjectura se estas "práticas colaborativas" não constituiriam um "arremedo de reconciliação social, como se o estado do mundo pudesse ser retificado com um pouco de boa vontade e alguns louváveis exemplos" - como os que vimos aqui : dos comensais novayorkinos, da ágora resisual, e do biogás tailandês (em Tiravanija) ; da desterritorialização geo-psi californiana (em Tellez) ; da "escultura viva" ou "campo imantado" pela língua (em Haaning); do "motor-home" compartilhado via website, do próprio Tiravanija; ou, por fim, do jardim de esculturas liliputianas e do parque semiótico, enquanto sitio de signos ressemeados (em Foerster). (GALARD, 2005, p. 11). Seriam "espaços de negociação" que permitiram novos "engates interculturais" (" aiguillages"), entre Argentina, Tailândia e Inglaterra, em Tiravanija; entre Venezuela, México e Estados Unidos, em Téllez; entre Dinamarca, França, Turquia e Holanda, em Haaning, e entre as cidades do México, Rio de Janeiro, Nova Déli e Kassel, em Dominique Forester. Pergunta-se, portanto, se estes espaços substitutivos funcionam efetivamente como elementos de recomposição dos espaços políticos, ou se eles assumem tão somente a função de seus substitutos paródicos.É possível afirmar, segundo alguns críticos, apesar da aposta de Bourriaud, que essas manifestações baseadas na colaboração, como as da arte relacional, operam como "formas de reparação de um Estado degradado". (GALARD, 2005:13). Elas seriam uma "racionalização", uma "atividade compensatória", uma "ideologia da reparação" que prospera sobre "um fundo de sentimento de culpa" (GALARD, 2005:19) inseparável do trabalho de luto ainda em curso pela morte das vanguardas, que "não ataca do ponto de vista político a causa verdadeira", a saber : a "implosão do social", como dizia Jean Baudrillard (BAUDRILLARD, 1982 :53). Essa tentativa de restaurar o vínculo social supostamente roto tem como pressuposto a substituição da política como espaço do dissenso ou do conflito por uma visão consensual de sociedade baseada nas ideias de tolerância ou transparência social. É difícil admitir afinal, que no circuito artístico, seja galeria, museu ou parque se configure, ainda que provisoriamente, "espaços para descobrir novos dissensos", na expressão de Jacques Rancière, haja vista que estas intervenções aderentes à dita realidade existente - na ausência da mediação da forma artística ou do gesto estético - resultam da colaboração de artistas, curadores, massmídia, e terceiro setor, entre outros parceiros. Essas ações, além disso, realizadas com frequência em espaços públicos - como em ocupações, por exemplo, de edifícios abandonados - com a colaboração de "agentes sociais", quando o próprio artista não assume esta função, como nas intervenções de Javier Téllez ou Rirkrit Tiravanija, podem ser confundidas com as iniciativas de ordem social, ou assistencialista, que implicam uma estética difusa, apaziguada, conciliatória muito distinta da "beleza intensa ou inquietante senão vertiginosa" que parece, frente a essa arte colaborativa, renegada a outra época. (GALARD, 2005, p. 53).

31 Radicalizando essa crítica podemos ainda indagar se o voluntarismo das vanguardas históricas fundado no artista-inventor, herdeiro da noção romântica de gênio, não teria sido substituído, nestas manifestações, pelo voluntariado do artista-manager, enquanto 
"excepcional organizador", uma vez que "a habilidade para a gestão passa a ser, agora, a primeira qualidade do artista relacional, gerente de eventos conviviais, atilado e autoritário empresário de operações simbólicas" (GALARD, 2005 :s/p) : "Nessa direção, me sinto - confirma o artista italiano Mauricio Cattelan - cada vez mais um editor ou empregador, e cada vez menos um artista" - ao menos no sentido da tradição moderna em arte. (CATTELAN apud OBRIST, 2006:15). É preciso examinar, em outros termos, se na tentativa de suprir a ausência de políticas sociais, o que teríamos nos espaços de arte relacional ou radicante é uma sociabilidade glamourizada, fictícia porque factícia, um espaço polido e desdramatizado, um simulacro, enfim, da sociabilidade dita real porque fundada na imprevisibilidade e nos conflitos, tal como se manifesta ordinariamente no espaço público.

Jacques Rancière, por seu turno, acredita que "arte coletiva" promovendo a "partilha do sensível“ pode se opor aos espaços de sociabilidade edulcorada. Em uma reação à recepção estereotipada do público, essas manifestações promoveriam, na língua do autor, uma "autêntica política do anônimo" (RANCIÈRE, 2005:74). Esta última noção, contudo, não possui, nele, sentido substancial ou ontológico, uma vez que o autor não a identifica a determinado grupo social, como às ditas minorias. Rancière caracteriza, de modo singular, o "anônimo" como "coletivo de enunciação e de manifestação que identifica sua causa e sua voz com qualquer outra, com as de todos aqueles que não têm direito de falar" (RANCIÈRE, 2004:85). Em resumo: essas manifestações dariam visibilidade às "formas de vida" que desafiariam as "práticas de consenso", pois ao "outorgar àqueles que não têm nome um nome coletivo" estariam "requalificando uma situação dada". (RANCIÈRE, 2005:83).

No centro da reflexão de Rancière temos, assim, a crença de que certas manifestações estéticas podem instaurar o "dissenso", noção que estaria na origem, segundo o autor, da ideia de política. O dissenso "não é um conflito de pontos de vista nem mesmo um conflito pelo reconhecimento, mas um conflito sobre a constituição mesma do mundo comum, sobre o que nele se vê e se ouve, sobre os títulos dos que neles falam para ser ouvidos e sobre a visibilidade dos objetos que nele são designados" (RANCIÈRE, 2006:374). Como vimos, contudo, há o risco destes "coletivos de enunciação" não adquirirem a força política almejada se a visibilidade do "devir anônimo" ficar restrita aos profissionais do metiér ou ao público habitué; ou, supondo sua veiculação pelas mídias - o que a princípio alargaria sua audiência - há a ameaça desses coletivos se dissolverem na universalidade abstrata da comunicação. Se, entretanto, não se acatar a hipótese da dissolução da arte na comunicação, ou seja, de que a arte só adquire existência quando paradoxalmente se "desrealiza", ao se tornar imagem (ou evento cultural); pode-se admitir, ao menos, que nessas manifestações haja um embate entre as representações que envolvem a arte e a imagem oficial da realidade difundida pelo discurso publicitário, transmitida pelos meios de comunicação, e organizada por uma ideologia light de consumo cultural. Desse embate resultaria assim, em outras palavras, a efetividade de uma "arte crítica" na qual "a estética adquiriria uma política própria" - na aposta pascaliana de Rancière - distinta da "estetização da política", considerada, aqui, como generalização do estético ou disseminação cultural (Ranciêre, 2005:86).

É interessante observar que o modo como diversos autores, no rastro de Maurice Blanchot, Georges Bataille, Gilles Deleuze, Félix Guattari e Roland Barthes, têm pensado a relação entre estética e política pode à primeira vista ser aproximado das noções de "arte colaborativa" de Bourriaud e de "política do anônimo", de Rancière. Não apenas no 
regime estético em sentido estrito, mas também nos regimes de trabalho, da clínica ou da amizade, Toni Negri, Michael Hardt; Jean-Luc Nancy; Mauricio Lazzarato, Giorgio Agambem ou Francisco Ortega vem figurando formas de vida que se furtam à dita "vida em comum" (como "comunidade identitária" ou "fusional") tais como : a "comunidade dos celibatários; a comunidade negativa; comunidades dos sem comunidades; a comunidade impossível; a comunidade de jogo ; a comunidade que vem; a comunidade da singularidade qualquer". São diferentes designações de formas "não unitárias", "não totalizáveis", "não filialistas" de comunidade; ou ainda: são "comunidades feitas de singularidades" - porque irredutíveis tanto ao "individualistmo" como ao "comunialismo". (PELBART, 2003:28-51).

Essas formas de comunidade não podem, contudo, ser equiparadas às noções de arte relacional ou de política do anônimo, sem mais, porque intentam na resistência ao rolo compressor do evento, "a criação em estado nascente" (GUATTARI, 1992:115). Ressalte-se, como exemplo, dessa resistência o trabalho da Cia Teatral Ueinzz, em São Paulo, composta por pacientes e usuários de serviços de saúde mental, coordenada por Peter Pelbart, que se furta seja a "arte institucionalizada", na expressão de Félix Guattari, seja a jubilação conversacional da política institucional e do terceiro setor, como indica o próprio nome do grupo: Ueinzz: "uma língua que significa a si mesma, que se enrola sobre si, língua exotérica, misteriosa, glossolálica” (PELBART, 2000 :99).

Em síntese, retomando o fio da meada: na tentativa de "reconstruir pontes", à qual nos referíamos, entre os anos 1960 e 1970 e os anos 1990 e 2000 o equívoco de Bourriaud, segundo Éric Alliez, foi relacionar as noções de "micropolíticas do desejo" e de "revolução molecular", ao modo de Guattari, à prática de negociação democrática fundada em um consenso esteticamente comunicável da arte relacional. De fato, os "focos de singularização", fruto da "transferência de singularidade do artista criador de espaço para a subjetividade coletiva", ou seja, "o novo paradigma estético" na novilingua do último Guattari é subsumida, em Bourriaud, ao "novo universal da comunicação", enquanto "democratização alternativa". (ALLIEZ, 2008:s/p). É importante ressaltar, contudo, que a "porta estreita da comunicação", por onde esvaece o "desejo revolucionário" - como sentencia Alliez a partir de Eric Toncy,- é inoperante na tentativa de compreender as referidas figuras da comunidade por vir, que vão a contrapelo da generalização do estético e da gentrificação cultural das últimas décadas (ALLIEZ, 2008, s/ p).

Destaque-se, por fim, como quarto problema, que os livros de Bourriaud são militantes porque se reportam a certa arte contemporânea, objeto de críticas e curadorias anteriores do autor. Bourriaud foi co-fundador e diretor do Palais de Tokyo de 2000 até 2006, curador de arte contemporânea da Fundação Gulbenkian de 2008 à 2010, e da Fourth Tate Triennal, em 2009, intitulada Altermodern, além de editor de Documents sur l'Art, de 1992 a 2000. De modo que o recorte de seus livros faz-nos refletir também sobre a relação entre a tarefa da crítica e a função curatorial; ou, mais precisamente, se Bourriaud, enquanto teórico da arte, não visaria a certificação de suas curadorias, e, enquanto curador, não almejaria a legitimação de seus textos críticos. É o que pode sugerir o modo de enunciação oscilante de seus livros, situado entre a descrição e a prescrição, esta última evidenciada no subtítulo do livro "Arte Radicante": "por uma estética da globalização." (BOURRIAUD, 2009b). Na tentativa de compreender o modo de inscrição desses projetos engajados socialmente nos mecanismos de produção cultural é preciso refletir, assim, sem receio, sobre a relação entre a tarefa da crítica e a função de curador, como no caso da crítica de 
Obrist e Bourriaud que certificaram com seus textos sobre arte relacional o ato de curar, e vice-versa. Entre descritivo e prescritivo esses curadores exibem as obras selecionadas como sendo representativas da "forma-função relacional", reduzindo-as ao aspecto da participação do público, à revelia, inclusive, de alguns artistas referidos em seus textos, que rejeitaram, no calor da hora, essa classificação (GILLICK, 2006:96). De tal modo que alguns artistas tidos por Bourriaud como relacionais, segundo a tipificação do curador coartista, têm concebido, eles próprios, "o cenário da exposição", assumindo a função de "artista-curador". (FOERSTER apud PATO, 2013:279). Nesse sentido, esses artistas questionam a ideia de curadoria como "um conjunto de relações que elevam o gênero (expositivo, de "fazer exposições") à condição de obra de arte" (PATO, 2013, p. 81). È a posição, por exemplo, de Gonzalez-Foerster que, aqui, comentamos: "Bourriaud é obcecado pela ideia de fabricar um movimento, dar nomes às coisas. Para mim, é um modelo um pouco antigo (porque relativo ao afã taxonômico ou classificatório da historiografia da arte de viés positivista herdado do século passado). Acho que ele tem uma compreensão de certas coisas (como as mudanças no imaginário do alto-modernismo à produção pós-vanguardista do presente); mas, por outro lado, tem a obsessão do historiador da arte de descrever as coisas de uma determinada forma (segundo a intencionalidade de seu aproache metodológico). $\mathrm{E}$ isso às vezes é bom (porque concede certa legibilidade a cena artística marcada pela multiplicidade, senão incomensurabilidade de obras heterogêneas), mas, às vezes, é uma posição artificial" (haja vista que seu parti-pris faz tabula rasa do caráter sui generis de cada obra considerada de per si.) (FOERSTER apud PATO, 2013:270, parênteses nossos).

É necessário verificar, em outros termos, se intervenções que poderiam ter efeito disruptivo não acabaram neutralizadas no "gênero expositivo", em razão do novo "balanceamento de responsabilidade" pela autoria, entre artista e crítico-curador, uma vez que a este tem sido, agora, atribuídas não apenas a função de "expor, mas de coexecutar" (fundamentar e divulgar) o trabalho do artista, como vimos (HUCHET, 1997:42: parênteses nossos). Dito sem meias-tintas: além disso, as curadorias (sobretudo de instalações) acabam por converter os espaços em que ocorrem (como lugar de exposição ou de evidenciação de uma prática, no caso da arte relacional) em "espaços (institucionais) de acolhimento ou de hospitalidade" até quando abrigam intervenções que problematizam o próprio circuito artístico, conquistando, desse modo, o beneplácito do público. Essa ênfase no gênero expositivo em prejuízo do efeito disruptivo é nítida em mostras internacionais como a Documenta de Kassel ou a Bienal de São Paulo que acabam, muitas vezes, por destacar o poder do curador, fazendo com que o artista incorpore de tal maneira "seu papel de produtor verdadeiramente pré-conceituado pelo projeto curatorial que assume o risco de ter seu perfil mesclado ao do curador" (HUCHET, 1997:39). Fica, decerto, um problema em aberto, porque recente, o de saber se é possível no quadro da generalização estética do presente produzir uma "forma artística" que detenha algum enigma, que indicie algum segredo, mistério, - ou recuo : seja a transcendência ; ou o "belo difícil"; o que significa verificar no caso da arte relacional, se é possível agenciar um "acontecimento" - uma operação que evidencie a "independência incondicional do pensamento", superando o performativo ou a simples comunicação: o que Jacques Derrida denomina "rompante"; "improvável"; "o isso"; ou "o chegante" (DERRIDA, 2003 :78) - algo que não seja, enfim, mero evento cultural, ou apenas circulação "interessante" de signos porque "próximo do curioso e do acicate; que atrai, mas não cativa ; que aferroa, mas não consegue nem ferir ou incitar"; ou seja, verificar como é 
possível, numa palavra, que se articule na forma artística ou gesto estético, negação (ou transgressão) sem negaceados (GALARD, $2004: 162$ ).

\section{BIBLIOGRAFIA}

ADORNO T., Teoria Estética, São Paulo, Martins Fontes, 1982.

ALLIEZ E., "Post-scriptum sur l'esthétique relationelle: capitalisme, schizofrénie et consensus", in Multitudes, no. 34, Paris, Éditions Amsterdam, automne, 2008.

AMBROZY L., O blogue de Ai Weiwei: escritos, entrevistas e arengas digitais 2006-2009, São Paulo, Martins Fontes, 2013.

BAUDRILLARD J., À sombra das maiorias silenciosas: o fim do social e o surgimento das massas, São Paulo, Brasiliense, 1982.

BISHOP C., "Antagonism and Relationnal Aesthetics", in October, no. 110, 2004.

BOURRIAUD N., "Estética relacional, a política das relações"; in 27ª̣. Bienal de São Paulo: seminários, L. LAGNADO (org.), Rio de Janeiro, Cobogó, 2008.

BOURRIAUD N., Estética relacional, São Paulo, Martins.

BOURRIAUD N., Pós-produção: como a arte reprograma o mundo contemporáneo, São Paulo, Martins Fontes, 2009a.

BOURRIAUD N., Radicante: por ume estética da globalização, São Paulo, Martis Fontes, 2009b.

BURGER P., Teoria da Vanguarda, São Paulo, Cosac Naify, 2008.

CARERI F., Walscapes: o caminhar como prática estética, São Paulo, Editora G. Gili, 2013.

CAUQUelin A., Arte Contemporânea. São Paulo, Martins, 2005.

CYPRIANO F, "Mostra binacional discute conceito de frontera", in Folha de São Paulo, 31/08, 2005.

COHEN R., Performance como linguagem, São Paulo, Perspectiva, 1988.

DERRIDA J., A universidade sem condição, São Paulo, Estação Liberdade, 2003.

FAVARETTO C. F., "Impasses da arte contemporânea", in Comunicações e artes em tempo de mudança, 1966-1991, AJZENBERG (org.), São Paulo, ECA-USP, SESC, 1991.

faVARETto C. F., "Do significado ao uso", in Jormal de Resenhas, n6. São Paulo, Discurso Editorial, outubro, 2009.

FOSTER H., El retorno de lo real: la vanguardia a finales de siglo, Madrid, Akal, 2001.

GALARD J., A beleza do gesto, São Paulo, Editora da Universidade de São Paulo, 1997.

GALARD J., “Estetización de la vida: abolición o generalización del arte?”, in La abolición de la arte, A. DALLAL (org.), México, UNAM, 1998.

GALARD J., La Beauté à outrance: réflexions sur l'abus esthétique, Paris, Actes Sud, 2004. 
GALARD J., “Arte, transfiguração e encontro no mundo contemporâneo: metáforas pétreas”, in Colóquio Gemas da terra: imaginação estética e hospitalidade, palestra proferida em 25/03, org. SESC Pompéia, Mímeo, 2005.

GENETTE G., L'oeuvre de l'art: immanence et transcendence, Paris, Éditions du Seuil, 1994.

GILLICK I., "Contingent Factors: A Response to Claire Bishop's Antagonism and Relational Aesthetics", in October n. 115. New York, MIT Press, hiver, 2006.

GUATTARI, F., Caosmose: um novo paradigma estético, São Paulo, editora 34, 1992.

HUCHET S., "Instalação, alegoria, discurso", in Trilhas n.6, Campino, Editora da Unicamp, 1997.

LYOTARD J.F., L'assassinat de l'experience par la peinture: Monory, Paris, Le Castor Astral, 1984.

LYOTARD J.F., Moralidades pós-modernas, Campinas, Papirus, 1996.

LYOTARD J.F., O inumano: considerações sobre o tempo, Lisboa, Estampa, 1997.

OBRIST H.U., Arte agora: em 5 entrevistas, São Paulo, Alameda, 2006.

OBRIST H.U., Don't Stop, New York/Berlin, Published by Sternberg, 2006a.

PELBAR P.P., Vida Capital: ensaios de biopolítica, São Paulo, Iluminuras, 2003.

PELBART P.P., A vertigem por um fio: políticas da subjetividade contemporânea, São Paulo, Iluminuras, 2000.

RANCIÈRE J., A partilha do sensível: estética e política, São Paulo, Editora 34, 2005.

RANCIÈRE J., Sobre políticas estéticas, Barcelona, Museu d'Art Contemporani de Barcelona y Servei de Publicacions de la Universitat Autônoma de Barcelona, 2005a.

RANCIÈRE J., Malaise dans l'esthétique, Paris, Galilée, 2004.

RANCIÈRE J., “O dissenso”, in A Crise da razão, A nOvaEs (Org.), São Paulo, Companhia das Letras, 2006.

RANCIÈRE J., O espectador emancipado, São Paulo, Martins Fontes, 2012.

StAHEl U. (org.), Ai Weiwei: Interlacing, São Paulo, Museu da Imagem e do Som, 2013.

ZIZEK, S., Bem-vindo ao deserto do Rea!: cinco ensaios sobre o 11 de Setembro e datas relacionadas, São Paulo, Boitempo, 2003.

\section{NOTAS}

1. Essa genealogia do "caminhar como prática estética" foi reconstituída, de modo semelhante, por Francesco Careri (CARERI, 2013). Esse autor, e arquiteto, narra, passo a passo, a "experiência ligada ao caminhar" reconstituindo as passagens do dadaísmo ao surrealismo (1921 a 1924), da Internacional Letrista a Internacional Situacionista (1956-1957), e do minimalismo a land art (1966-1967). Careri destaca as "visitas-excursões" antiartísticas do grupo dadá, organizadas por Tristan Tzara, em 1921, a "lugares banais", "insossos", de Paris ou seus arredores, escolhidos segundo "critérios gratuitos", como a um "jardinzinho em torno da igreja Saint-Julien-lePauvre", em 1921, comentada por André Breton (CARERI, $2013: 74$ ); as “deambulações" surrealistas pela "parte inconsciente" da cidade moderna, sob as ruínas das reformas urbanísticas de Haussmann, como a descrita por Luis Aragon em "Le paysan de Paris", de 1924, em busca de "surpresas ou revelações extraordinárias", ou seja, da "sensação do maravilhoso" no 
cotidiano", trazidas pelo "vento da eventualidade", no achado verbal de Breton (CARERI, $2013: 81)$; as "derivas" situacionistas que "visavam a habitar de formas alternativas a cidade", nos quais" o tempo útil seria substituído pelo tempo lúdico-construtivo" (e não pelo tempo onírico, no sentido surrealista) indiciadas nas maquetes, de 1956 a 1974, de Constant, de "alojamentos comuns construídos a partir dos elementos móveis, constantemente remodelados" : uma "arquitetura megaestrutural labiríntica" construída com "base sinuosa do percurso nômade" (tendo como ponto de partida, acampamentos ciganos) ; por fim, o autor destaca os "atravessamentos" dos artistas da land art como meio de apropriação de espaços desérticos, seja por um ato de "transformação física" da "paisagem atravessada", como em "A Tour of the Monuments of Passaic", de Robert Smithson, que, em 1967, se "atinha à mutação (do território) do natural no artificial e vice-versa" (CARERI, 2013 :148); seja por um "ato de transformação simbólica", que não deixa rastros permanentes no território, como nas caminhadas de Richard Long que, com seus "passos que são como as nuvens, pois vêm e vão", visam registrar tão somente as mudanças na "direção dos ventos, da temperatura, dos sonhos" (CARERI, 2013 : 132-134-148). Dessas caminhadas resultariam, no mapeamento de Careri, uma "história da cidade percorrida que vai da cidade banal dadá a cidade entrópica de Smithson, passando pela cidade inconsciente e onírica dos surrealistas e pela lúdica e nômade dos situacionistas" (CARERI, 2013 :28). Essa "genealogia caminhante" teria como último elo a experiência "andare a zonzo" (vagar a esmo, ou a pas perdus) pelo "territori attuali" empreendida pelo grupo Stalker (em referência a "zona mutante" do filme de mesmo título de Andrei Tarkovski), sob a coordenação do próprio autor, nos anos 1990. Tomando como "modelo de reflexão e jogo" a noção acima mencionada de New Babylon de Constant - de uma "cidade móvel para uma população nômade sem fronteiras" -, Careri enfatiza, na narração dessa experiência, os "vazios urbanos" : "espaços que habitam a cidade de modo nômade, deslocando-se sempre que o poder tenta impor uma nova ordem" (CARRERI, 2013 :157). Essa noção de "terrain vague" (de raiz dada), de "espaços intersticiais", de "índole indefinida e metamórfica", e, portanto, de "difícil representação" (CARERI, 2013 :159-160) - que não deve ser identificada à noção de espaço vazio tradicionalmente entendido como espaço público, praça, rua, ou parque, no sentido do projeto moderno em arte e arquitetura de extração construtiva - está muito próxima, como veremos a seguir, da noção de "plataforma" ou "estação" de Nicolas Bourriaud. Em linhas gerais, pode-se concluir que a "cultura da errância" orienta os dois autores.

2. Pensemos a propósito desta relação entre arte e comunicação o ativismo na web do artista chinês Ai Weiwei que com seu blog de fotos e depoimentos, de 2005 a 2009, e, mais recentemente, com seus posts no microblog no Twitter visa, em cruzada digital pelos direitos humanos, denunciar o autoritarismo do governo chinês. Ai Weiwei, que opera como "rede, como empresa", enquanto "voz política", como caixa de ressonância social, ou "agent provocateur", assume como referência (desde o período no qual viveu na comunidade artística chinesa em Nova York, de 1981 a 1997, antes de regressar, portanto, à China onde seria preso e censurado) Marcel Duchamp e Andy Warhol: "Acho que a minha posição e o meu modo de vida são a minha arte mais importante" (AI WEIWEI, apud STAHEL, 2013 :38). Pelo exame de seus posts pode-se advogar que não há em Weiwei nem mera comunicação, nem culto a personalidade do artista no sentido da fetichização da autoria uma vez que sua posição equivaleria a de um "coletivo de enunciação", o que significa dizer que sua voz seria o meio pelo qual se instauraria o "dissenso" (a "polifonia do anônimo"), entendidos como "o conflito sobre a constituição mesma do mundo comum" (no caso, a sociedade chinesa), nos termos de Jacques Rancière, aos quais retomarem os. (RANCIÈRE apud NOVAES, $1996: 374$; (parênteses nossos). 


\section{RESUMOS}

O artigo mostra que na arte relacional, na expressão de Nicolas Bourriaud, dos anos 1990 e 2000, é visível a tentativa de embaralhar arte e vida, o que a remete ao imaginário das vanguardas artísticas do século XX. Procura, contudo, distinguir o projeto moderno de superação da relação entre arte e vida da proposta de "arte colaborativa", que tomamos como sintoma da arte contemporânea e cujo propósito seria se aproximar do mundo da vida. Seu objetivo é assim examinar se essas "práticas colaborativas e interdisciplinares" articulam os elementos do presente no gesto estético ou na forma artística, de modo a relacionar metáfora, estética e política, ou se essas práticas, ao contrário, atestam a neutralização da poética e o desvanecimento da política. Para tanto indagamos, a partir de Jean Galard, se esses espaços substitutivos podem funcionar efetivamente como elementos de recomposição dos espaços políticos, ou se eles correm o risco de assumirem a função de seus substitutos paródicos. Ou seja, se na tentativa de suprir a ausência de políticas sociais, o que teríamos nos espaços de arte relacional é uma sociabilidade glamourizada, fictícia - um simulacro da sociabilidade dita real que é fundada na imprevisibilidade e nos conflitos.

L'article démontre que "l'art relationnel" (selon l'expression de Nicolas Bourriaud) des années 1990 et 2000 constitue manifestement une tentative de mélanger l'art et la vie, en écho à l'imaginaire des avant-gardes artistiques du XXe siècle. D'un point de vue du dépassement de la relation entre art et vie, on vise surtout à distinguer le projet moderne, initié au début du XXeme siècle, de cette proposition "d'art relationnel" considéré comme symptome de l'art contemporain. L'objectif est d'examiner ces "pratiques collaboratives et interdisciplinaires". Et comment elles articulent les éléments du présent dans le geste esthétique, de manière à relier ces pratiques dans le domaine artistique et politique. Ou, au contraire, si de telles pratiques attestent la neutralisation de la poétique et l'évanouissement de la politique. Pour autant on se demande, à partir de Jean Galard, si ces modes d'action peuvent fonctionner comme des éléments de recompositions des espaces politiques, ou s'ils risquent de prendre la fonction de leurs remplaçants parodiques ; c'est-à-dire d'une sociabilité fictionnelle, simulacre de la sociabilité dite réelle qui, quant à elle, fonctionne sur l'imprévisibilité et sur les conflits.

\section{ÍNDICE}

Mots-clés: art contemporain, esthétique relationnelle, communication, politique, curateur Palavras-chave: arte contemporânea, estética relacional, comunicação, política, curadoria

\section{AUTOR}

\section{RICARDO NASCIMENTO FABBRINI}

É professor de estética do Departamento de Filosofia da Faculdade de Filosofia, Letras e Ciências Humanas da USP. É autor de « O Espaço de Lygia Clark» (Atlas, 1994) e « A arte depois das vanguardas » (Editora da Unicamp, 2002). USP, São Paulo, Brasil. 